\title{
GERENCIALISMO A LA VASCA: UN ANÁLISIS DEL DISCURSO DE LA "NUEVA CULTURA DE EMPRESA"
}

\author{
Basque Style Managerialism: A Discourse Analysis of the \\ "New Enterprise Culture»
}

CARLos J. Fernández Rodríguez*

Universidad Autónoma de Madrid

\begin{abstract}
RESUMEN
Las ideologías gerenciales son una de las manifestaciones más características de nuestra época. En un contexto neoliberal donde la globalización de los mercados, las nuevas tecnologías y la creciente intensificación de la competencia son vistos como importantes desafíos empresariales, la necesidad de mejorar los procesos de gestión e implicar cada vez más tanto a directivos como a empleados en la buena marcha de las empresas se ha convertido en la piedra angular del discurso empresarial contemporáneo. Esto exige nuevas políticas empresariales que se están difundiendo por todas partes, incluyendo por supuesto a Euskadi. En este territorio, la «Nueva Cultura de Empresa» impulsada por la patronal guipuzcoana ADEGI se está instalando en muchas empresas. En este artículo, el objetivo será el de analizar el discurso asociado a esta nueva cultura gerencial y sus implicaciones en el terreno de la representación de los trabajadores y la configuración del sistema de relaciones laborales.

Palabras clave: gerencialismo, management, Euskadi, relaciones laborales, sindicatos

\section{ABSTRACT}

Management ideologies are one of the most remarkable features of our age. In a neoliberal context where globalization of markets, new technologies and the intensification of competition are perceived as important challenges for business, the need to improve management processes as well as involve both managers and employees in the performance of corporations has become the cornerstone of contemporary business discourse. This requires new business policies that are spreading everywhere, including the Basque Country. In this territory, the "New Enterprise Culture» promoted by the Guipuzcoan employers' association ADEGI has been adopted by many firms. In this article, the goal will be to analyse the discourse associated with this new managerial culture, as well as its implications in terms of worker representation and the configuration of the employment relations system.
\end{abstract}

Keywords: managerialism, management, Basque Country, industrial relations, trade unions

\footnotetext{
* Correspondencia a: Carlos J. Fernández Rodríguez. Facultad de Ciencias Económicas y Empresariales. Universidad Autónoma de Madrid, c/Francisco Tomás y valiente, 5, 28049-Madrid. - carlos.fernandez@uam.es - https://orcid.org/0000-0002-2959-8195

Cómo citar: Fernández Rodríguez, Carlos J. (2019). "Gerencialismo a la vasca: un análisis del discurso de la "nueva cultura de empresa"»; Lan Harremanak, 41, 231-259. (https://doi.org/10.1387/lan-harremanak.20788).
}

Recibido: 25 abril, 2019; aceptado: 20 junio, 2019

ISSN 1575-7048 - elSSN 2444-5819 / (c) 2019 UPV/EHU 


\section{SUMARIO}

1. Introducción.-2. El discurso del management contemporáneo: ideas principales.-3. La "nueva cultura de empresa» de ADEGI y su modelo de relaciones laborales. 3.1. Un contexto muy concreto: crisis económica y soluciones neoliberales. 3.2. La "Nueva Cultura de Empresa»: de PwC a las propuestas de ADEGI. 3.3. La "Nueva Cultura de Empresa», ADEGI y el Gobierno Vasco.-4. Conclusiones.-5. Bibliografía

\section{Introducción ${ }^{1}$}

Las ideologías gerenciales son una de las manifestaciones más características de nuestra época. En un contexto histórico caracterizado por la globalización de los mercados, el desarrollo de las nuevas tecnologías y la creciente intensificación de la competencia empresarial, y en el que la hegemonía ideológica se encuentra claramente anclada en los valores del neoliberalismo, la necesidad de mejorar los procesos de gestión e implicar cada vez más tanto a directivos como a empleados en la buena marcha de las empresas se ha convertido en la piedra angular del discurso empresarial contemporáneo. Este discurso, también conocido como discurso gerencial o discurso del management (y al que se han dedicado numerosas investigaciones académicas: ver por ejemplo Enteman, 1993; Collins, 2000; Parker, 2002; Gantman, 2005; Fernández Rodríguez, 2007; du Gay, 2012; Alonso y Fernández Rodríguez, 2013a, 2013b y 2018; Klikauer, 2015; Fernández Rodríguez y Medina-Vicent, 2017), aunque desarrollado en su configuración primordial en el mundo de los negocios anglosajón, se ha difundido y extendido a lo largo y ancho del globo, influyendo de forma creciente no solamente en la forma en que las corporaciones definen su actividad en los mercados y configuran la organización del trabajo, sino incluso en la manera en que se reforman los servicios públicos, el mercado de trabajo o las políticas sociales.

\footnotetext{
1 Este artículo se basa en una investigación, encargada y financiada por el sindicato ELA, para explorar las características y contenidos de la denominada "Nueva Cultura de Empresa». Dicha investigación dio lugar a un informe, entregado en abril de 2019, y publicado por la Fundación Manu Robles-Arangiz. Para el desarrollo de la versión final del texto también se ha contado con el apoyo del proyecto de investigación del Ministerio de Ciencia, Innovación y Universidades con referencia PGC2018-097200-B-I00. Quiero agradecer a Unai Oñederra y Jon Las Heras sus comentarios en fases anteriores de la investigación.
} 
Las ideologías gerenciales no son únicamente descripciones de cómo los empresarios ven el mundo, sino auténticas políticas que, una vez implantadas, modifican de forma profunda el funcionamiento de las organizaciones, instituciones y mercados, por supuesto en favor de los intereses empresariales. Impulsan, así, una mercantilización creciente en todos los aspectos de la vida social, contribuyendo a reforzar el paradigma neoliberal en el que estamos instalados, y justificando las nuevas relaciones de poder existentes. Por su extraordinaria influencia en los avatares políticos y socioeconómicos de nuestro tiempo, y por representar una de las manifestaciones más prototípicas de lo que serían los «discursos del presente» (Alonso y Fernández Rodríguez, 2013a), desde luego merece la pena que la investigación en ciencias sociales siga prestando atención a estas ideas en sus diversas manifestaciones.

En el caso que nos ocupa aquí, el objetivo de este artículo es el de dar cuenta de una de dichas manifestaciones del discurso del management o "discurso de la empresa» que está teniendo lugar en un espacio muy concreto: Euskadi. En la última década, se ha desarrollado de forma progresiva por parte de las patronales vascas un nuevo instrumento estrechamente vinculado con las ideologías gerenciales: la llamada "Nueva Cultura de Empresa», impulsada por la patronal guipuzcoana ADEGI (Asociación de empresas de Gipuzkoa), y que supone una forma novedosa de adaptación de los principios básicos del gerencialismo a un contexto muy concreto, como es el de la Comunidad Autónoma del País Vasco (CAPV), marcada por un sistema de relaciones laborales diferenciado del marco espańol. Para ello, este trabajo se va a dividir en tres secciones. En la primera, lo que se va a presentar es un análisis somero de las principales ideas de este discurso de la empresa en su versión más contemporánea, describiendo los principales conceptos que maneja y sus prescripciones para el mundo de las organizaciones (y por supuesto para aquellos que trabajan en las mismas). En segundo lugar, haremos un análisis de la ya señalada "Nueva Cultura de Empresa», como ejemplo representativo de este tipo de nuevas políticas empresariales inspiradas en el discurso del management más reciente. Finalmente, en una sección de discusión se reflexionará sobre el impacto de dichas políticas en las relaciones laborales de la CAPV y las implicaciones que estas nuevas ideologías gerenciales pueden tener en la configuración de los sistemas de relaciones industriales contemporáneos.

\section{El discurso del management contemporáneo: ideas principales}

¿Qué es el discurso del management o discurso gerencial? Para aproximarnos a esta cuestión, es imprescindible que tengamos presente un elemento que, de manera sutil pero intensa, ha contribuido a su consolidación: el uso de ciertas palabras, de términos concretos, de un nuevo lenguaje, casi una "neolengua» (Willmott, 2007). Los trabajadores en las organizaciones contemporáneas, especialmente aquellos con cierta cualificación, se ven expuestos en su centro de tra- 
bajo, de forma ocasional o recurrente, a ser interpelados por un discurso muy peculiar, que emana de la dirección de la empresa y que está plagado de conceptos que han hecho fortuna: términos como emprendedor, iniciativa, empatía o liderazgo han pasado a formar parte del imaginario del trabajo contemporáneo, y la referencia a que «tenemos que gestionar mejor» como único horizonte futuro se ha convertido en un auténtico mantra repetido hasta la extenuación por corporaciones, expertos, políticos y representantes institucionales de la gobernanza económica y financiera (Micklethwait y Wooldridge, 1998; Collins, 2000; Fernández Rodríguez, 2007; Alonso y Fernández Rodríguez, 2013a, 2013 b y 2018). Es imprescindible, de acuerdo con este discurso, facilitar que las empresas sean competitivas en un mercado cada vez más globalizado e inestable, lo que significa que tanto los individuos como la sociedad deben asumir la necesidad de afrontar cambios profundos que permitan la supervivencia de sus negocios y mercados. Y ello evidentemente va a suponer, por ejemplo, que se promuevan nuevas formas de gestión tanto de lo público como de lo privado (du Gay, 2012) y, sobre todo, prácticas más intensas y comprometidas. Si bien estas últimas han formado siempre una parte del corpus central de las ideologías empresariales, recientemente han adquirido incluso más visibilidad, gracias a la incorporación de nuevos dispositivos tecnológicos que permiten medir, de forma más sofisticada, el rendimiento en el trabajo.

El gerencialismo representaría lo que algunos autores como Luc Boltanski y Ève Chiapello (2002) han denominado el nuevo espiritu del capitalismo, u otros como Laval y Dardot (2013), una de las manifestaciones de la nueva razón del mundo neoliberal. Ese nuevo espíritu del capitalismo sería la ideología que justifica y hace atractivo el compromiso de las personas con el sistema capitalista y el trabajo en la empresa en el contexto contemporáneo, el cual difiere significativamente de la organización burocrática weberiana que impulsó el capitalismo industrial de la postguerra y los "treinta años gloriosos» (Alonso y Fernández Rodríguez, 2013a). El capitalismo neoliberal descansa sobre otros valores, pues en el escenario de la globalización ya no se necesita una planificación racional y a largo plazo de la producción, que exigía una enorme estabilidad en los factores productivos (controlada mediante una regulación extensa de la economía y una paz social relativa ganada a partir del diálogo social); para ser exitoso en los mercados de la globalización, turbulentos no solamente por la rápida circulación de los capitales y la financiarización de la economía, sino por los gustos cambiantes de unos consumidores cada vez más segmentados en preferencias y rentas, se necesita de forma insoslayable una gestión flexible, que descansa sobre la reorganización veloz de los procesos de trabajo, la adaptación veloz a nuevos canales y tecnologías, el uso intensivo del marketing y la comunicación y la capacidad de responder con celeridad a cambios en los gustos de los consumidores (Lash y Urry, 1987; Harvey, 2007; Alonso y Martínez Lucio, 2006; Alonso y Fernández Rodríguez, 2013a). Así, el compromiso tanto de gestores como de empleados es 
imprescindible, ya que deben ser receptivos a cambiar de un día para otro sus condiciones de trabajo (lo que hacen, cómo lo hacen, dónde lo hacen), a aportar ideas e información, a formarse y actualizar sus conocimientos, a asumir cargas de trabajo inesperadas, y todo ello sin garantías de éxito y con una enorme incertidumbre de fondo. Esto requiere, evidentemente, una enorme motivación y entusiasmo por parte de la plantilla, un verdadero autodisciplinamiento (Revilla y Tovar Martínez, 2011) que evite el conflicto en el espacio de trabajo y acreciente la productividad y capacidad de adaptación de la plantilla. ¿Cómo persuadir a los empleados de las corporaciones de que es necesario implicarse más, asumir riesgos de los que antes, por el marco laboral y la cultura empresarial existente durante el fordismo, habían estado más o menos protegidos? Pues se hace desarrollando un nuevo diagnóstico de la situación existente, en el que se reconstruye la narrativa en torno a cómo funciona el mundo y que permita transformar la angustia asociada a la incertidumbre y el riesgo en una posibilidad de éxito profesional y personal (Boltanski y Chiapello, 2002). Este discurso gerencial se construirá a partir de las ideas de diferentes expertos presentes en algunas instituciones centrales en la generación de conocimiento sobre la empresa, $\mathrm{y}$ a las que se aludirá posteriormente.

¿Cuáles son las claves de esta narrativa o discurso que asociaríamos al gerencialismo contemporáneo? Consiste en describir una realidad que, aunque relativamente reciente, ya está plenamente instalada entre nosotros, y en la que están presentes una serie de tendencias que es más que probable que sigan intensificándose en el futuro. En lugar de hacer énfasis en los riesgos de este nuevo escenario, lo que se trata es de desarrollar un storytelling que enfatice los elementos positivos de la nueva situación. De este modo, y tal como se ha señalado en algunos trabajos anteriores (ver Fernández Rodríguez, 2007; Alonso y Fernández Rodríguez, 2013a y 2018), aunque el pasado fuese plácido y seguro, y el presente sea inseguro y desafiante, podemos afrontar un futuro con garantías si somos capaces de asumir la necesidad del cambio organizacional y personal y aceptamos que la fluidez es el nuevo estado de las cosas. Directivos y trabajadores deben asumir así el cambio, y no echar de menos la seguridad de tiempos pretéritos; la actitud correcta es la de rechazar ese pasado de seguridad por plúmbeo y falto de dinamismo, y apostar por nuevos retos que exigen, evidentemente, mayor compromiso y flexibilidad. Adiós a los horarios, las rutinas y la estabilidad: es imprescindible acometer nuevas tareas, reciclarse, ser móvil y dinámico, y tener la capacidad de, en todo momento, satisfacer las necesidades de un cliente cada vez más caprichoso y exigente (Fernández Rodríguez, 2007).

Trastocar y reorganizar la empresa para adaptarse a ese cliente-rey que quiere productos cada vez más sofisticados y a mejor precio, y que además desea y quiere satisfacer dicho deseo de forma inmediata, es el reto central al que se enfrentan los gestores hoy en día. ¿Cómo hacerlo? Flexibilizando la organización al máximo, convirtiéndola en poco más que flujos de trabajo interconectados en continua re- 
visión e interconexión (Boltanski y Chiapello, 2002). La empresa en red, paradigma organizacional contemporáneo, es una organización fundamentalmente antiburocrática, despojada de límites y regulaciones, que empodera a los trabajadores con el objetivo de convertirlos en intraemprendedores (empleados que actúan como auténticos empresarios de sí mismos: ver Santos Ortega y Muñoz-Rodríguez, 2018), delegando responsabilidades en ellos con el fin de que estos asuman parte de los riesgos inherentes a la actividad empresarial. Así, por una parte, deberíamos comportarnos como emprendedores, que son de alguna manera los «héroes» de nuestro tiempo, el modelo social a seguir: deberíamos de hecho poner en marcha una empresa y, así, generar riqueza y trabajo. De hecho, las políticas de empleo se están orientando a combatir el desempleo fomentando la creación de start-ups, siguiendo las recomendaciones de la Unión Europea cuyo modelo social europeo descansa, en la actualidad, en estrategias basadas en la activación personal, el emprendimiento y la flexiguridad (ver Keune y Serrano Pascual, 2014). No obstante, y si pese a ello no lo hacemos, al menos nuestro comportamiento como empleados debería seguir unas pautas de dedicación, esfuerzo y compromiso similares a las que tendríamos si el negocio fuese nuestro, adquiriendo nuevas competencias y siendo creativo e innovador para ayudar a que la empresa encuentre nuevos nichos de negocio y formas novedosas de incrementar la tasa de beneficio en diferentes ámbitos del proceso productivo.

Ello tiene importantes implicaciones en el clima laboral: lo positivo sería asumir ese rol del emprendedor, mostrando entusiasmo por el trabajo que realizamos y convirtiéndonos, en nuestro comportamiento cotidiano y en todas las facetas de la vida, en auténticos empresarios de nosotros mismos; lo negativo sería actuar contra ese entusiasmo, contra la flexibilidad, contra el compromiso. Lo negativo para la empresa serían así los burócratas, los acomodados y, particularmente, los sindicalistas, que con sus continuas reivindicaciones y amor por la regulación, entorpecen el funcionamiento adecuado de los negocios. Por tanto, un objetivo clave de los gerentes deberá ser el de generar las condiciones para que esos trabajadores motivados se conviertan en el centro de la organización, marginando o deshaciéndose de elementos molestos. Y al mismo tiempo, desde las patronales se tratará de influir en los gobiernos para reformar, en profundidad, la legislación laboral y la negociación colectiva, con el fin de dar más fuerza al empresario a la hora de decidir, de forma unilateral, cuáles van a ser las condiciones laborales (apostando además por una fragmentación de las relaciones de empleo al perseguir contratos lo más individualizados posible). Para ello, se va a demonizar a los sindicatos con diversas estrategias, presentando a estas instituciones representativas de los intereses de los trabajadores como anacrónicas, anticuadas, pertenecientes a otros tiempos, una auténtica reliquia del pasado sin apoyos reales, a las que han abandonado los jóvenes y que deben excluirse del mundo laboral por su freno a la flexibilidad que exige el trabajo contemporáneo (sobre todas estas cuestiones, ver Fernández Rodríguez, 2007). 
Y es que la empresa debe estar formada por personal extremadamente motivado, preocupado exclusivamente por su desempeño individual, y cuyos vínculos con la organización trasciendan el marco formal de la relación laboral: existirá así, o al menos este debería ser el objetivo, una adscripción emocional, en el que la identificación con la firma por parte del empleado debería ser total, hasta el punto en que se convierte casi en nuestra familia: se trata de la denominada "cultura de empresa", fomentada en las grandes empresas japonesas pero acogida con entusiasmo también en otros contextos, y en la que la empresa pasa a "tratarnos bien», pues felicita el cumpleaños a los empleados, invita a una cena de empresa por $\mathrm{Na}$ vidad, organiza actividades lúdicas con jefes y compañeros, cuenta con un coach que nos asesora y diseña actividades para afrontar el estrés, etc. Toda esta labor de «hacer feliz al empleado» se desarrolla en el marco de esta nueva cultura empresarial que va a demandar a cambio máximo compromiso por parte de los empleados de la organización. Esta «cultura de empresa» requerirá, para su consolidación, contar con un nuevo tipo de manager, un «líder carismático», que busca convencer más que ordenar, siendo exigente, pero también tolerante, $\mathrm{y}$ cuya ambigua gestión "postmoderna» descansará en «valores» (ibid., 2007).

¿Cómo se difunden estas ideas y visiones? Como se ha señalado en diversos trabajos, hay una red de instituciones y actores que colaboran en la construcción y difusión de esta mirada al mundo empresarial y los valores asociados a la misma (Mazza y Álvarez, 2000; Fernández Rodríguez, 2013; Dundon y Rafferty, 2018). Por ejemplo, las escuelas de negocios o business schools, un espacio en el que se forman la mayoría de las élites directivas internacionales: son centros muy importantes en términos de educación superior especializada para directivos, porque no solo proporcionan un conocimiento técnico para los ejecutivos, necesario para el desempeńo de sus tareas cotidianas, sino sobre todo transmiten de forma implícita o explícita unos valores morales en relación al trabajo y al comportamiento deseado y esperado de las personas (Wedlin, 2006). Estas escuelas han proliferado a lo largo de las últimas décadas, y el territorio español no es una excepción, con ejemplos bien conocidos como ESADE, IESE, ESIC, Deusto o el Instituto de Empresa (hoy conocido como IE Business School) (Fernández Rodríguez y Gantman, 2011). Las más conocidas de estas escuelas, en su mayoría instituciones norteamericanas de élite (Harvard, Columbia, Chicago, Wharton) tienen un papel clave al contribuir al desarrollo de teorías gerenciales que - de forma progresiva y siguiendo una dinámica de lo que DiMaggio y Powell (1983) definen como isomorfismo institucional- se propagan y terminan incorporadas a los programas académicos del resto de las escuelas de negocios, contribuyendo a que directivos de distintos espacios geográficos y orígenes culturales se familiaricen y hagan suya una mirada muy particular (e influida por una perspectiva muy anglosajona) del funcionamiento de las empresas. Otra institución muy relevante en la cristalización del discurso empresarial son las grandes empresas de consultoría, como las muy conocidas KPMG, 
Deloitte, Ernst \& Young, McKinsey o PriceWaterhouseCoopers (PwC). Todas estas firmas, centradas en un modelo de negocio basado en el asesoramiento a empresas, son enormemente influyentes: sus demandados informes, sean para empresas o para gobiernos, marcan una línea de actuación siempre orientada a proteger los intereses empresariales, y que se inspira en las principales ideas del discurso del management (Kipping y Engwall, 2002).

Otro actor muy importante en la difusión del discurso gerencial va a ser el representado por los denominados expertos en gestión o gurús del management, en cuyos libros exhortan a directivos y empleados a la aceptación y adopción de las nuevas lógicas de gestión. Lo que los gurús proponen es poner en práctica nuevas medidas en las empresas que las llevarán al éxito y, en algunos casos, proporcionarán además recetas para el éxito personal en el mundo de los negocios (Huczinsky, 1993; Collins, 2000; Fernández Rodríguez, 2007). Son muchas las teorías gerenciales que han alcanzado popularidad a lo largo de los años (inteligencia emocional, reingeniería de procesos, creación de valor para el accionista, etc.) y, además de eminentes figuras internacionales de gran influencia (Tom Peters, Peter Drucker, Michael Porter, Rosabeth Moss Kanter, C.K. Prahalad), también han tenido un papel importante otras a un nivel más local. Por ejemplo, en el caso de Euskadi, cuenta de hecho con algunos gurús autóctonos, como José Ignacio López de Arriortúa, conocido en su época de gloria en la industria del automóvil como Superlópez, hoy consultor empresarial; o Koldo Saratxaga, de la empresa vasca $K 2 K$ emocionando, cuyos textos relatan, siempre con gran emoción y pasión, transformaciones empresariales que tienen como objetivo poner en el centro «a las personas» (ver Saratxaga, 2007). Así, el esfuerzo combinado de todos estos canales, a los que podemos sumar otros (think tanks, prensa económica) contribuye a la popularización de las ideas gerenciales entre los cuadros directivos de las empresas, y a la aparición de nuevas prácticas de gestión distintas. En este nuevo estilo de gestión, el poder se va a ejercer de forma distinta: el mando se va a ejercer de forma más sutil, con apelaciones continuas a los intereses compartidos, con muchas referencias a lo emocional como pegamento de la organización, y a priori con formas suaves - el soft management, al que han aludido grandes figuras del pensamiento como Bourdieu (1998) o Deleuze (1999)—, que contrastan con el estilo autoritario de los managers de época pretéritas. Los centros de trabajo acogerán nuevas figuras como la del coach, una especie de «entrenador» que asesora de forma individualizada a los directivos sobre su "gestión de las emociones», y nuevas prácticas (mindfulness etc.) tanto para relajarse como para fortalecer los equipos de trabajo. Estas prácticas se convertirán en habituales en las organizaciones con el objetivo de favorecer un cambio cultural en la organización: esto es, que por fin se instale en la empresa una nueva cultura organizativa, seductora, basada en el compromiso y la confianza, y en la que los intermediarios entre capital y trabajo no tengan razón de existir, lo que supone evidentemente una amenaza muy importante para los sindicatos. 
Un ejemplo casi paradigmático de estas nuevas prácticas empresariales que tratan de perseguir un cambio cultural radical es la ya citada «Nueva Cultura de Empresa» que se está implantando en el ámbito de la CAPV. Promovida por la patronal guipuzcoana ADEGI, se ha convertido en el santo y seńa de un nuevo enfoque de las relaciones laborales en el País Vasco, asumido tanto por Confebask como por el Gobierno Vasco del PNV liderado por el lehendakari Urkullu. Esta nueva filosofía gerencial no solamente recoge el nuevo espíritu del gerencialismo contemporáneo, sino que además representa una ruptura considerable respecto al modelo tradicional de relaciones laborales vascas. Por ello, es importante comprender qué valores están detrás de dicha filosofía de gestión, y qué implicaría para el conjunto de los trabajadores vascos - y para el modelo sindical en Euskadi- que dicha cultura de empresa se implantase. A ello dedicaremos el análisis pormenorizado que se presenta en la siguiente sección.

\section{La «nueva cultura de empresa» de ADEGI y su modelo de relaciones laborales}

\subsection{Un contexto muy concreto: crisis económica y soluciones neoliberales}

Para comprender la génesis de esta "Nueva Cultura de Empresa», es preciso retroceder unos ańos para entender el contexto en el que aflora. Y que no es otro que el de una crisis económica galopante en el conjunto de Espańa, resultado de un tsunami alimentado por la coincidencia del fin de una burbuja inmobiliaria que había generado un modelo productivo muy específico y dependiente del endeudamiento, y una crisis financiera de carácter internacional que generó restricciones al crédito y graves turbulencias en los mercados, cuyas consecuencias fueron el cierre, rescate o absorción de importantes entidades bancarias (García y Ruesga, 2014). Tras el crac de 2008, rápidamente se generó una contracción inaudita de la actividad económica, que tuvo como resultado las mayores tasas de desempleo desde que existe la Encuesta de Población Activa (hasta un 27\% en 2013), con más de la mitad de la población juvenil desempleada y una situación social dramática con miles de desahucios, quiebras familiares y un déficit público en aumento ante los crecientes gastos de los seguros de desempleo (Laparra y Pérez Eransus, 2013; Fundación FOESSA, 2014; Rocha, 2014). Desde la UE, particularmente la Comisión Europea, se planteó la necesidad de afrontar la grave crisis de la economía espańola mediante el recurso de las llamadas "políticas de austeridad», también aplicadas en otros países del entorno: tanto el PSOE de Rodríguez Zapatero como, con más ahínco y determinación, el Gobierno del Partido Popular de Rajoy pusieron en marcha una serie de medidas, basadas en duros recortes sociales y diversas reformas orientadas a contentar a los mercados internacionales (con el fin de rescatar a la banca y mantener bajo control la prima de riesgo de la deuda pública española), pese al negativo im- 
pacto social de estas intervenciones (Alonso, 2014). Y junto a lo anterior, a lo largo de todo este período se desplegarán, además, medidas adicionales en el terreno de las políticas públicas de empleo que estarán vinculadas a los paradigmas de la activación y la flexiguridad que dominan la política de la Unión Europea (sobre esto, ver Fernández Rodríguez y Serrano Pascual, 2014; Keune y Serrano Pascual, 2014).

Uno de los símbolos de estas políticas de ajuste neoliberal fueron las diferentes reformas laborales aprobadas a lo largo del período 2010-2012. La más profunda, ya con el gabinete de Rajoy en el poder, fue la de 2012, recogida en el Real Decreto-ley 3/2012, de 10 de febrero, de medidas urgentes para la reforma del mercado laboral. Esta reforma tuvo un impacto inmediato en las condiciones laborales en el conjunto de España, al cambiar por completo la correlación de fuerzas existente entre capital y trabajo, debilitando de forma significativa el poder sindical y facilitando, consecuentemente, una mayor atomización de las condiciones de trabajo en las empresas, en un sistema productivo post-industrial marcado por importantes desigualdades entre regiones (Rocha, 2014; Meardi, 2014). Este cambio en la correlación de fuerzas o, mejor dicho, esa consolidación de la desigualdad entre las partes, objetivo histórico de la patronal española desde hace décadas (ver Fernández Rodríguez y Martínez Lucio, 2014), se consiguió en parte con la aprobación de esta legislación. La magnitud e importancia de las medidas aprobadas es evidente: posibilidad de las empresas de «descolgarse» de los convenios; prioridad del convenio a nivel empresa sobre los convenios de carácter sectorial o estatal; o el fin de la denominada ultra-actividad, recurso que tradicionalmente permitía resguardar algunas de las conquistas del comité de empresa en situaciones de dificultad en las negociaciones y decaimiento del convenio colectivo. Todo esto sirve para reforzar la flexibilidad en el sistema productivo español, permitiendo un fuerte ajuste salarial que permitía a las empresas ganar competitividad en un contexto económico marcado por una enorme incertidumbre. Pese a una oposición sindical que incluyó dos huelgas generales en todo el Estado y numerosos paros sectoriales, la reforma se acabó aprobando en el Parlamento. Las medidas comenzaron a tener efecto casi de inmediato, con diversos descuelgues de empresas, políticas de reducción salarial nunca vistas, y decaimiento y no renovación de numerosos convenios colectivos (Fernández Rodríguez, Ibánez Rojo y Martínez Lucio, 2016). En poco tiempo, tuvo importantes efectos sobre las condiciones laborales de los trabajadores, contribuyendo a recortes de derechos y condiciones laborales, incluyendo salarios. Ello ha generado una fragmentación de las relaciones laborales sin precedentes en la historia reciente, y una situación excepcional que merece la pena comentarse.

$\mathrm{Y}$ es que esta última reforma laboral, que ha continuado una larga trayectoria de reformas inspiradas en una perspectiva neoliberal puestas en marcha tanto por los gobiernos del PP como los del PSOE desde hace décadas, ha ser- 
vido, fundamentalmente, para desequilibrar las relaciones laborales en favor de los intereses de las patronales y los empresarios, relaciones que en el caso espańol siempre habían sido, en todo caso, muy desiguales debido a la situación de subordinación sindical desde los inicios del período democrático y a la óptica neoliberal que ha dominado las políticas españolas (Fernández Rodríguez y Martínez Lucio, 2014). El poder de las patronales a la hora de negociar es mucho mayor ahora, ya que tienen la capacidad de desengancharse de los convenios, desentenderse de las condiciones anteriores, fragmentar el ámbito de negociación. Esto desvirtuaría la idea de diálogo social que ha fundamentado las relaciones industriales en las sociedades democráticas, pues dialogar implica contar con dos interlocutores válidos, legitimados y con unas fuerzas similares que permitan una negociación equilibrada. De la negociación, se ha pasado a una situación de imposición, sea esta explícita o tácita. En el escenario actual, algunos representantes de las patronales son conscientes de que el hecho de maltratar a los sindicatos puede tener consecuencias futuras negativas para ellos, como por ejemplo la radicalización de los representantes de los trabajadores: ello genera más conflictos laborales, un abandono de los sindicatos mayoritarios en favor de sindicatos más combativos, y una mayor judicialización de las relaciones laborales (Fernández Rodríguez, Ibáñez Rojo y Martínez Lucio, 2016). Sin embargo, y pese a estas advertencias, la reforma se ha implantado y ha permitido no solamente una notable precarización de las condiciones laborales, sino construir las bases para la adopción de un modelo de nueva economía de plataformas que está empezando a arraigar en España con consecuencias muy negativas sobre la calidad del empleo creado.

El caso del País Vasco en este contexto es peculiar. En la primera fase de la crisis, hasta 2012, su comportamiento económico es un poco mejor que el del resto del Estado: es una zona todavía relativamente industrializada, con menores niveles de desempleo, una protección social más elevada y un nivel de bienestar relativamente alto. Está caracterizada además por un sistema de relaciones industriales diferenciado al del resto del Estado, donde los sindicatos ELA (Eusko Langileen Alkartasuna) y LAB (Langile Abertzaleen Batzordeak) acumulan la mayoría de los delegados sindicales desde hace mucho tiempo (más o menos un $60 \%$ del total, siendo ELA el sindicato mayoritario con diferencia, con más del $40 \%$ de la representación), y donde la combatividad sindical, particularmente de ELA, había contribuido a frenar relativamente las iniciativas de desregulación procedentes tanto del gobierno central como de la propia CAPV. Ya desde principios de la década de los 2000, ELA había asumido un giro estratégico en su actividad sindical (Elorrieta, 2016; Kortabarria, 2016), lo que le había llevado a crecientes encontronazos con la patronal vasca que se recrudecerían con la crisis. Tras la aprobación de la reforma laboral, lo que veremos es un conflicto creciente ante el cambio de óptica de Confebask (Confederación Empresarial Vasca) respecto a cómo reorientar las relaciones laborales en Euskadi (en buena 
medida influida por los planteamientos de ADEGI, la patronal guipuzcoana), y que va a encontrar una gran receptividad en el Gobierno del PNV. Pese a que el PNV votó en el Parlamento español contra la reforma de 2012, desde la patronal vasca y posteriormente desde el Gobierno de Vitoria se va a vislumbrar una ventana de oportunidad para provocar un cambio en la situación de las relaciones laborales vascas, que, desde el punto de vista de ambos actores (empresarial y gubernamental), se habían "estancado», achacando la responsabilidad del bloqueo en particular al sindicato ELA (al cual en muchas ocasiones no se le menciona directamente, dando rodeos como «la primera fuerza sindical», pero claro, no es difícil saber cuál es la primera fuerza sindical en Euskadi). ¿Cómo se manifestaba esta visión? No solamente en las declaraciones públicas de distintos actores institucionales, sino también en la documentación que manejaban y en el asesoramiento recibido por parte de empresas de consultoría bien conocidas como PriceWaterhouseCoopers (PwC) o K2K Emocionando, la consultora de Koldo Saratxaga. Frente a la resistencia de ELA a la forma en que se estaba planteando el diálogo social desde hacía ya muchos ańos, y que llevó a una negativa a participar en las mesas de diálogo, el Gobierno Vasco afrontó una estrategia distinta, que ha sido vista por el sindicato como un intento antidemocrático de marginarlo (ver ELA, 2018). Dicha estrategia tendría un doble objetivo. Por una parte, se trataría de facilitar acuerdos en minoría que superasen los posibles bloqueos que pudiese hacer ELA (seguida generalmente por LAB) a la negociación colectiva, para lo que se trataría de impulsar un nuevo modelo de diálogo social, ya en funcionamiento tras la aprobación del Decreto de creación de la Mesa de Diálogo Social el pasado mes de enero, y que permite la firma de acuerdos sin necesidad de contar con el sindicato mayoritario. Y, por otra parte, se trataría de influir, de alguna forma, en las negociaciones a nivel de empresa, espacio en el que ELA ha contado históricamente con una enorme fortaleza gracias a su lucha, basada en largas huelgas financiadas con una caja de resistencia. Para poder actuar en ese ámbito, la estrategia utilizada por la patronal vasca con el apoyo evidente del Gobierno Vasco ha sido la llamada «Nueva Cultura de Empresa», una nueva filosofía gerencial que trata de construir un marco distinto de relación entre dirección y trabajadores que superaría el marco institucional de la negociación colectiva (sería, según la patronal guipuzcoana ADEGI, impulsores de este proyecto, una "nueva vía de «interlocución directa» con los empleados», con la que no se pretendería «obviar» la negociación colectiva sectorial), y que merece la pena explorarse.

\subsection{La «Nueva Cultura de Empresa»: de PwC a las propuestas de ADEGI}

Para comprender mejor en qué consiste «Nueva Cultura de Empresa», lo lógico es acudir, en primer lugar, a los discursos que los propios impulsores presentan al público, y que se tratarán de descifrar aquí siguiendo la metodología del análisis del discurso ya puesta en práctica en trabajos anteriores a la hora de 
analizar algunos de los discursos empresariales más relevantes (ver Fernández Rodríguez, 2007 y 2011). El análisis del discurso tiene como objetivo interpretar los discursos poniéndolos en relación con un contexto social concreto, tratando de descifrar los significados ocultos o latentes presentes en las palabras que alguien ha enunciado, pues un discurso no son solamente palabras, sino la construcción y la prescripción de una realidad determinada, de unas prácticas y acciones concretas. Ello exige evidentemente un análisis que, en el plano de la sociología, se ha enunciado como socio-semiológico o socio-hermenéutico, cuyos fundamentos están descritos en algunos de los principales textos de metodología cualitativa de España (ver así Alonso, 1998; Conde, 2009), y que es el que se tratará de poner en práctica en esta sección del artículo.

En primer lugar, debemos tener presente por qué se pone en marcha la «Nueva Cultura de Empresa». Como se había comentado anteriormente, la reforma laboral de 2012 había supuesto, de alguna manera, abrir una ventana de oportunidad para la patronal en el conjunto del Estado en términos de desequilibrar la balanza a su favor, como ya se ha indicado antes. Esto, de hecho, tiene mucho que ver, en el caso vasco, con una imagen, un discurso, extendido entre el empresariado y el Gobierno Vasco, de que las relaciones laborales vascas son, en cierto sentido, "demasiado conflictivas», y es por ello difícil llegar a acuerdos. De hecho, en un informe de la consultora PriceWaterhouseCoopers de 2018 titulado Temas candentes de la economía vasca. La visión de los empresarios todavía se hace referencia a la necesidad de construir un escenario diferente que supere la situación actual, en la que, de acuerdo a los empresarios vascos, "se ha instalado una cultura de confrontación en la empresa» (PriceWaterhouseCoopers, 2018: 22). La idea central que expresa de forma velada este informe, radiografía de la mirada del empresariado vasco hacia lo que sucede en Euskadi en muchos ámbitos, es que dicha situación de confrontación habría impedido la aplicación real de la reforma laboral, que a su juicio hubiera sido muy positiva. Curiosamente, en el informe se hace referencia a que dicha posición sindical impide la firma de convenios colectivos, por exigir condiciones demasiado ambiciosas que ponen en riesgo la viabilidad de las empresas. En el informe se señala lo siguiente:

La fuerte presión sindical hace que los convenios, al agotar su periodo de vigencia sin renovarse, decaigan. A pesar de ello, las empresas, que podían aprovechar la coyuntura para cambiar el modelo de retribución y recortar las condiciones laborales de sus trabajadores, no lo han hecho porque una decisión así sería incompatible con el mantenimiento de la paz social necesaria para funcionar (ibid., 22).

Estos comentarios son de máximo interés. El empresariado vasco considera que los convenios decaen porque los sindicatos exigen demasiado y, por tanto, no se firman. Sin embargo, la realidad de la reforma laboral es que, en el resto del Estado, su aplicación supuso, sobre todo en los primeros años, un bloqueo sin precedentes de la negociación colectiva a nivel estatal por parte de las patronales, con una caída signifi- 
cativa del número de convenios firmados que, tras largas negociaciones, se firmaron con una cesión, por lo general, importante, por parte de la parte sindical. Que en el País Vasco se mantuviesen unas condiciones laborales algo mejores es probable que fuese fruto precisamente de esa estrategia de fuerte presión sindical, que ha hecho que, durante algún tiempo, el impacto de los recortes en las condiciones laborales de los trabajadores vascos no alcanzase las dramáticas condiciones de otros lugares. Sin embargo, desde el lado de los empresarios, esta presión se considera una estrategia dańina y reprobable, y se ponen nombre y apellidos a los culpables:

«La estrategia de confrontación laboral va contra las personas que trabajan en Euskadi porque les impide tener convenios colectivos. Es una paradoja, porque en teoría tendría que ser mucho más fácil negociar en Euskadi con un sindicato nacionalista que lo contrario. En opinión de las empresas consultadas, el sindicalismo trabaja por su supervivencia con una mirada de las cosas que remite al pasado, agudizando los conflictos y el enfrentamiento nosotros-ellos. Inevitablemente el punto final de esa postura es que la gente vaya evolucionando a prescindir del sindicato» (PriceWaterhouseCoopers, 2018: 23).

De estos comentarios se desprenden dos importantes datos. El primero procede del texto entrecomillado, probablemente una cita literal de un empresario vasco, del que se infiere que el que está favoreciendo el bloqueo es un sindicato nacionalista, y no sería aventurado inferir que puede tratarse, en concreto, de ELA (por su mayor representatividad). Esto se entendería, por parte de PwC, como una anomalía. Por otra parte, en la segunda parte del párrafo, aparece uno de los argumentos clásicos del discurso gerencial: la irrelevancia sindical en el mundo contemporáneo. El sindicato entiende que en el mundo de la empresa hay un conflicto explícito, algo que niegan los empresarios. Esta contraposición entre conflicto y armonía reproduce la clásica oposición entre una mirada a la sociedad bien marxista (conflictiva) o bien funcionalista (armónica), aunque lo interesante es que el empresariado vasco, en línea con los argumentos más típicos del nuevo management, se situaría a sí mismo como el futuro, en contraposición con los sindicatos que serían el pasado. Es como si los conflictos entre el capital y el trabajo ya estuvieran superados. El catalogar al sindicalismo como algo obsoleto, que solamente «mira al pasado» de forma casi nostálgica mientras el mundo ha cambiado de forma total, es una estrategia de descalificación de su rol y de su labor histórica. Esto sirve para pedir que el sindicalismo militante y exigente deje paso a otra cosa distinta, a un sindicalismo "responsable». Y de hecho, en el informe aprovechan para apuntar que esa insistencia en el conflicto les ha separado de los jóvenes, y ha llevado a que la gente se desencante de su labor (cuando por otra parte, en otros foros de la derecha mediática se ha acusado al sindicalismo, en general, justo de lo contrario: de haberse acomodado, aburguesado, apoltronado, y es que la cuestión es dañar su imagen pública, hagan lo que hagan). Lo que la gente querría, y que coincidiría con el planteamiento de los empresarios, es que se llegase a acuerdos: 
No se pueden hacer proyectos de futuro si no hay un compromiso entre los empresarios y los trabajadores de la empresa. La falta de objetivos compartidos es un problema del conjunto de las empresas vascas, según los participantes en este informe. Los empresarios más activos en buscar fórmulas de acuerdo se enfrentan con sindicatos que no les permiten avanzar (ibid., 23).

Los que intentarían llegar a acuerdos, en todo caso, parecería que son los empresarios, frente a la cerrazón y cabezonería de los sindicatos, que son un freno, que no permiten avanzar. Como se puede leer, se presenta a los actores sindicales como una rémora del pasado, un freno a las aspiraciones empresariales. Y claro, en este contexto, llega una propuesta ciertamente radical:

En este escenario, el empresariado vasco cree que existen mecanismos de gestión de las personas que no pasan por la negociación con los sindicatos. A su juicio, no es difícil imaginar un modelo de empresa trasparente en el que trabajadores y empresarios tengan una interlocución permanente y directa. De esta manera, los sindicatos seguirían formalmente en la empresa pero perderían su capacidad negociadora (ibid., 23).

Este planteamiento supone en cierto modo un auténtico jaque a las relaciones industriales tal y como se han entendido en el reciente período democrático. Parece claro que hay una idea de construir un nuevo marco de negociación de condiciones laborales ajeno a los canales de interlocución recogidos en el Estatuto de los Trabajadores. Se presenta una alternativa al bloqueo del diálogo social... mediante la eliminación de este. Si el empresariado vasco se ha situado en esta perspectiva, de acuerdo al informe de $\mathrm{PwC}$, ha sido probablemente por la aparición de nuevas propuestas procedentes de las patronales vascas. Y de ellas, la más destacada sin duda es la mencionada "Nueva Cultura de Empresa», impulsada por ADEGI. ¿Qué objetivos persigue dicha cultura de empresa? Fundamentalmente, plantear la necesidad de superar el marco vigente de relaciones laborales, que deberá ser sustituido por una nueva cultura organizacional:

Tras la reflexión estratégica 2012-2015 de ADEGI, lo que pretendía ser una transición ordenada y progresiva en el tiempo hacia una nueva cultura de empresa basada en la confianza entre las partes, se ha convertido en una necesidad imperiosa como consecuencia fundamentalmente del nuevo escenario resultante tras el $7 \mathrm{de} \mathrm{ju-}$ lio de 2013 (ADEGI, 2014: 3).

Cuando se habla de nuevo escenario es preciso aclarar que en esa fecha decayó finalmente el convenio del metal gracias a que se hace efectiva la reforma laboral y, debido a que la reforma laboral no permitía una situación de ultra-actividad, se tiene la oportunidad por parte de la patronal de presionar para cambiar las condiciones de la negociación colectiva. De hecho, ante esta situación los sindicatos, ELA entre ellos, incluso presentaron una demanda (desestimada finalmente por el Tribunal Superior de Justicia del País Vasco) contra ADEGI y 
la Federación de Empresarios del Metal de Gipuzkoa para que se reconociera la vigencia del convenio del metal en dicha provincia y, también, por las recomendaciones que desde ADEGI se empezaron a hacer a sus socios, a los que se incitaba a utilizar la oportunidad para plantear un cambio radical de su modelo de relaciones laborales. Esto se afirma de forma explícita en el mismo informe:

Estamos ante un cambio de época que requiere una transformación de la cultura de empresa, impulsando una interlocución directa con las personas de nuestras empresas sin olvidar el cumplimiento de las obligaciones para con los representantes legales de los trabajadores. Ello implica un cambio cultural en el seno de cada empresa, tanto por parte de la propiedad/dirección como de los trabajadores. Pero el cambio lo debemos liderar nosotros, todas las empresas de forma colectiva. Nada cambiará si nosotros no cambiamos, aunque ello conlleve salir de nuestra zona de confort (ibid., p. 3).

En este párrafo, se condensan los elementos centrales de la filosofía de la nueva cultura de empresa. La idea es que «debemos salir de nuestra zona de confort» (frase repetida hasta la saciedad en miles de libros de empresa y autoayuda) y asumir la incertidumbre actual es uno de los argumentos más habituales de los gurús de la gestión para que la gente esté dispuesta a renunciar a derechos conquistados como es el de la estabilidad y la posibilidad de un proyecto de vida. La forma de conseguir que la gente acepte esto es, como es evidente, tratando de convencerles (paso previo a forzarles), a través de un esfuerzo cultural importante: cambiar la cultura significa, fundamentalmente, que la gente valore de forma distinta cosas que solía apreciar y desear (seguridad, tranquilidad) y apueste por otras cosas (riesgo, cambio). La "Nueva cultura de empresa» tiene el objetivo de cambiar la forma de pensar de los trabajadores, en un contexto histórico como el actual marcado por las denominadas "guerras culturales».

Eso sí, no todo se expresa de forma rotunda. Aunque el objetivo de ADEGI es superar el marco de relaciones laborales actual, se cuidan muy mucho de decir que van a vulnerarlo de forma dramática: así, se reconoce que se respetarán las obligaciones con los sindicatos, aunque lo cierto es que el impulso de estas prácticas van vinculadas a que los trabajadores de las empresas acepten un nuevo conjunto de medidas que afectan a cuestiones clave como los salarios, sin pasar por los sindicatos:

Por ello, el objetivo deseable es aumentar la productividad y contener o variabilizar los costes salariales. Es decir, es necesaria una revisión anual de los salarios que contemple la evolución de la productividad de la empresa, estableciendo sistemas de retribución variable que incluyan incentivos orientados hacia la mejora de la competitividad. Ligar salario y productividad no supone ni rebajar salarios ni menor coste laboral para las empresas: el aumento de la productividad beneficia a todos (íbid., p. 4).

Así, la idea es fundamentalmente la de introducir flexibilidad en las organizaciones, empezando por los salarios (que se vinculan por esquemas de parte va- 
riable a los resultados de las empresas), y hacer ver a los trabajadores que con el nuevo marco que ha permitido la reforma laboral, las condiciones históricas de un convenio no van a ser ya más derechos adquiridos, sino algo que puede perfectamente eliminarse si fuera el caso, empeorando de forma unilateral las condiciones de trabajo. Hay que aprovechar la oportunidad de imponer condiciones más ventajosas para los empresarios, lo que implica revisar todo:

En esta situación de cambio en el ámbito de las relaciones laborales derivado del decaimiento de una parte significativa de los convenios colectivos sectoriales provinciales debes comenzar identificando el origen de las condiciones laborales de los/as trabajadores/as de tu empresa. Debes respetar los derechos adquiridos por los/as trabajadores/as y conocer que las condiciones laborales recogidas en un convenio colectivo no constituyen derechos adquiridos. Revisa el histórico de los pactos de tu empresa, los contratos de trabajo y la estructura salarial de las nóminas. Con todo ello junto con un diagnóstico económico y organizativo de tu empresa, toma una decisión coherente y razonada que garantice la competitividad de tu empresa; objetiviza tu decisión (ibid., p. 4).

Obsérvese la argumentación: respeta los derechos pero cuidado... que lo negociado no es un derecho adquirido. Todo es revisable, modificable, desde cero: la recomendación (pues no olvidemos que se trata de un consejo, una sugerencia de ADEGI) es la de diagnosticar cómo están las cosas en la empresa y, desde ahí, proceder al ajuste que corresponda. Esto está en línea con la derogación del mecanismo de ultra-actividad del Estatuto de los Trabajadores, y que no tiene otro objetivo que poder revertir lo conseguido, incluyendo por supuesto los salarios:

Históricamente, la jornada anual de los diversos sectores de Gipuzkoa ha sido la menor de Espańa y significativamente inferior a la media. En cuanto a los salarios, Gipuzkoa presenta salarios superiores a los del resto de provincias de Espańa (ibid., p. 4).

Como se puede leer, los salarios son demasiado altos (de hecho se estimaba que en 2011 superaban en un $20 \%$ a los de la media del Estado), y las horas trabajadas, demasiado pocas. Se infiere del texto que esto no sería bueno, y que se está buscando un cambio de modelo porque, bajo estos parámetros, las empresas guipuzcoanas estarían perdiendo competitividad. Se hace una comparación con el resto del Estado que, por supuesto, no tiene en consideración factores como la productividad real, la organización del trabajo, la cualificación, etc. o el hecho de que países enormemente competitivos como los nórdicos cuenten con salarios todavía más elevados que los vascos.

Además, para garantizar el control de este proceso de cambio cultural (que enmascara un cambio material en las condiciones de trabajo), se va a perseguir el control total de la información dentro de la empresa, adecuándola a un escenario en el que el storytelling (la historia que se va a contar desde la empresa) cuente con la capacidad propagandística y de seducción suficiente para audien- 
cias tanto externas (la opinión pública, la administración) como internas (los trabajadores), imponiéndose al relato del resto de los actores (que son, evidentemente, los sindicatos):

Aquello que ocurre dentro de la empresa trasciende a la misma y sale al exterior de múltiples maneras, creando una corriente de opinión que se puede imponer como verdad absoluta. Si no lo hace la propia empresa nadie va a contar cuál es su punto de vista y las razones que le han llevado a tomar las decisiones. En consecuencia, si no queremos estar al albur de estos acontecimientos de forma pasiva, debemos de ser protagonistas de nuestra comunicación hacia el exterior (ibid., p. 5).

Comunicar: al final la clave es esta, el relato, la propaganda, la intención de parecer razonables, flexibles, moderados ante la opinión pública; se trata de decir que en la empresa somos buenos, que os queremos, que estamos todos en el mismo barco, que somos modernos y flexibles, aunque luego la intención parece que sea la de recortar salarios y derechos, introducir flexibilidad o incluso reprimir la acción sindi$\mathrm{cal}$. La idea latente es que hay que cuidar la imagen con buenas palabras (confianza, responsabilidad compartida, talento) aunque luego lo que suceda sea, en realidad, otra historia, no siempre tan hermosa. Buscar canales de comunicación con el trabajador con el objetivo de dinamitar el comité de empresa y sus atribuciones legales.

Una vez presentada en sociedad en 2014, la guía de la «Nueva Cultura de Empresa» pasó a difundirse entre los socios de ADEGI y posteriormente a ser asumida, en los siguientes ańos, por Confebask, que la ha considerado un instrumento esencial para esa transformación de las relaciones laborales en Euskadi. Progresivamente, numerosas empresas se han ido sumando a este modelo. La guía, mientras tanto, se ha actualizado a lo largo de estos años, y la tercera y, hasta el momento última versión, es de 2017. Si uno lee sus recomendaciones, es evidente que el objetivo de esta estrategia es el de implantar la ideología del management como herramienta de gobierno dentro de las empresas, por encima del marco institucional o del diálogo social:

...estamos ante un cambio de época que requiere sin duda una transformación de la cultura de las empresas hacia un proyecto compartido sobre la base de la confianza (ADEGI, 2017: p. 7).

La forma en la que se presenta la situación es prototípica del gerencialismo: en primer lugar, las alusiones al cambio de época, al fin de una forma de organizar las cosas, a la llegada de un escenario nuevo al que debemos adaptarnos porque no tenemos ningún control sobre los acontecimientos; en segundo lugar, las referencias a lo cultural, y no a lo material, como eje del cambio; y finalmente, las palabras mágicas, la "confianza», el "proyecto compartido», esto es, palabras inclusivas y retórica seductora para negar la existencia del conflicto en el espacio de trabajo. Además, a esto se añade la referencia a lo nuevo, a lo exitoso, lo internacional: 
Nos hemos inspirado fundamentalmente en las empresas de Gipuzkoa y asimismo hemos tomado como ejemplo países como Dinamarca, Suiza, Alemania o el ecosistema emprendedor de Boston, constatando que el cambio lo tenemos que liderar nosotros, todas las empresas de manera colectiva, ya que nada va a cambiar si no cambiamos nosotros, aunque ello conlleve salir de nuestra zona cómoda (ibid., 7).

La idea es que las empresas vascas se inspiren en lo moderno, y se citan para ello ejemplos seductores (lo que se hace en algunos de los países con renta per cápita más elevada del mundo), a la vez que se apremia a los gerentes a liderar el cambio. La prescripción del comportamiento, eje central de las ideologías del management, se expresa aquí de forma muy explícita: o te mueves o te mueven, y ello implica «salir de nuestra zona de confort». Ese cambio lo que implicaría es dejar atrás la confrontación, para dar paso a un nuevo sistema más inclusivo, cuasi corporativo, basado en compartir, en asumir juntos un proyecto. La metáfora de la sokatira a la trainera es, en este sentido, de gran interés: la alusión al mundo del deporte, siempre presente (a los gurús de los Estados Unidos les encanta poner ejemplos de equipos de béisbol o de fútbol americano; hace unos ańos, el método Guardiola era un ejemplo para las escuelas de negocios de toda España) y que sirve para remarcar la importancia del liderazgo y el trabajo en equipo:

...pasar de la sokatira a la trainera, generando relaciones de confianza para transitar de la confrontación a la colaboración entre sus personas, para entender la empresa como un proyecto compartido (ibid., p. 7).

En la trainera las barcas compiten entre sí, como en el mercado lo hacen las empresas, así que cada empresa-barco debe estar bien cohesionada para llegar a buen puerto:

Para que todas las personas de la empresa remen en la misma dirección y conseguir así que la empresa crezca. Para transitar de un modelo de confrontación a otro de colaboración sobre la base de la confianza entre todas las personas de la empresa (ibid., p. 11).

Remar en la misma dirección, sí, con el fin de colaborar sobre la base de la confianza, pero claro, ¿̇de qué confianza estamos hablando? Como el lector comprobará, en un contexto en el que se trata de implementar una reforma muy lesiva para los derechos y condiciones de los trabajadores vascos, hablar de confianza es, como mínimo, un brindis al sol. Lo que se ofrecen son palabras que suenan bien (acercarnos, escuchar, comunicar: todo muy cercano, muy emocional) pero que al final no dejan de ser ambiguas y con poca referencia a lo material que es lo que uno se está jugando en las negociaciones en los centros de trabajo. De alguna manera, la manera de integrar al trabajador es, como se ha 
señalado, cultural, con muchas referencias a la psicología positiva, vagamente espiritual y con la idea de construir algo en común, como una suerte de comunidad de feligreses. Obsérvese cómo se expresan estas ideas:

Para acercarnos y escuchar, comunicar, hacer partícipes a las personas y así conseguir su compromiso en la marcha y futuro de la empresa (ibid., p. 11).

Para situar a las personas en el eje, en el corazón de las empresas (ibid., p. 11).

Para que la forma de relacionarnos en la empresa no sea ajena a los valores individuales de las personas, haciendo coincidir en este ámbito lo que hago con lo que soy (ibid., p. 11).

También se hace referencia a los valores y las personas, dos palabras que en el vocabulario gerencial son centrales y profundamente ambiguas. ¿Qué significa que las personas son importantes? ¿Significa que vamos a respetar sus derechos? ¿Vamos a mejorar sus condiciones de trabajo? ¿A respetar sus órganos de representación? Y respecto a los valores, ¿a qué nos estamos refiriendo exactamente? ¿A los valores democráticos? Parece que los únicos valores que se dan por supuestos a los trabajadores son aquellos que tienen que ver con la dedicación total a la empresa, y que sus únicos proyectos vitales son los de servirla, sin entender que el trabajo asalariado suele ir acompañado de la disciplina. Generalmente, no es fácil alinear los proyectos individuales con los empresariales, pues uno en la empresa está más «a la orden» que a otra cosa (la democracia termina en la puerta de la empresa, que es un espacio muy jerárquico y desigual), y lo que se comparte es, por lo general, muy poco. Y, sin embargo, el mantra siempre es el mismo, el del proyecto compartido:

Las personas hacen la empresa, de ahí que ésta se ha de constituir en el entorno adecuado para que las personas puedan alinear sus proyectos personales con el proyecto compartido de empresa (ibid., p. 12).

Para ser capaces de construir este proyecto compartido es imprescindible que esta nueva cultura de empresa sea liderada por la dirección de la misma, que es interpelada para ello:

... ¿estás preparado para liderar la transformación cultural de tu empresa? (íbid., p. 13).

En resumen, lo que tenemos es un proyecto con unos objetivos muy concretos: generar un cambio cultural con el fin de que, en la empresa, todos sus miembros asuman un proyecto compartido. Sin embargo, hay una serie de elementos que debemos tener en cuenta en este proceso: en primer lugar, que se busca un proyecto compartido, pero en ningún momento parece entrarse en una discusión seria al respecto. Se dice que se va a escuchar a cada miembro de la organización, pero no se hace mención a una discusión colectiva y en torno a 
una agenda de temas concretos; en segundo lugar, que el liderazgo del proyecto compartido recae exclusivamente en la dirección de la empresa; y, finalmente, que se habla de confianza, pero las alusiones a los temas en los que se vincula dicha confianza no se explicitan. ¿Nos despedirá la empresa si los resultados no son los esperados? ¿Se escuchará nuestra opinión en cuestiones delicadas como la estrategia de la empresa?

De hecho, en el resto del informe de "Nueva Cultura de Empresa» se plantean distintas cuestiones técnicas en torno a la puesta en marcha de este cambio cultural, con estas referencias continuadas a liderar, generar confianza, comunicar y ahí, de repente... aparece una referencia mucho más material, que no es otra que la cuestión salarial:

...es necesaria una revisión anual de los salarios que contemple la situación de la empresa y la evolución de su productividad (ibid., p. 13).

Y aquí aparecen los salarios, probablemente una de las claves de la reforma. El informe dedica una sección completa a trabajar un tema importante porque supone adaptar la política retributiva de la empresa a las turbulencias de los mercados. En este sentido, el concepto que se va a manejar aquí va a ser el de la puesta en marcha de una hipotética participación en los resultados:

La participación de las personas tanto en la gestión como en los resultados, constituyen uno de los pilares fundamentales de la transformación que las empresas de Gipuzkoa han de impulsar para liderar en su seno una nueva cultura sobre la base de la confianza (ibid., p. 24).

Participar en los resultados y en la gestión: estas son palabras que podrían aludir a una mayor democracia industrial, pero que aquí parecen referirse más bien a una suerte de adaptación salarial que permita que los riesgos de la actividad empresarial se desplacen a los trabajadores. Aunque se argumenta que la adaptación salarial tiene consecuencias beneficiosas (mejora de la competitividad de la empresa, garantía de sostenibilidad futuro, adecuación de los costes laborales, mantenimiento del empleo y mayor compromiso de las personas), lo cierto es que se divide el salario entre una parte fija y una variable a expensas de los resultados de la empresa, lo que puede suponer un recorte salarial importante si estos no son buenos. En el informe, se especifican varios posibles modelos de reparto, basándose en el siguiente (y discutible) axioma:

Si la empresa gana las personas ganan, es un camino sin retorno (ibid., p. 24)

Sin embargo, esta presentación de las bondades de este modelo no tiene en cuenta, precisamente, que las empresas se ven expuestas a importantes vaivenes en sus resultados que tienen mucho que ver con la situación de globalización de 
los mercados y financiarización de las economías que hemos experimentado en las últimas décadas. Los casos de cierres injustificados, cambios accionariales, políticas de gestión de recursos humanos draconianas etc. están al orden del día en las noticias económicas. Y, en muchos casos, ofrecer una gran "confianza» a sus empleados no significa que se respeten luego los compromisos. En este sentido, lo cierto es que en la mayor parte del mundo donde existen mercados desregulados los comportamientos carentes de ética alguna por parte de gestores y directivos están a la orden del día, y si no suceden más a menudo es por la decisiva intervención y vigilancia tanto sindical como de los poderes públicos. Sin embargo, la «Nueva Cultura de Empresa» parece obviar todo este contexto:

Debemos transitar hacia una forma de relacionarnos en el que se tengan en cuenta los intereses de todas las personas/grupos de interés implicadas en la empresa $\mathrm{y}$, por tanto, ir alejándonos de las posiciones tradicionalmente mantenidas por unos y otros (ibid., p. 37).

Al final, de lo que se trata es de, de una forma unilateral, proceder a construir una nueva cultura empresarial en la que los canales tradicionales de negociación interna se vean sustituidos por unas relaciones nuevas, como se dice en el informe un «nuevo contrato social» (íbid., p. 33), en las que los distintos individuos y "grupos de interés» (término ambiguo donde los haya que, ¿incluye a los sindicatos?) traten de llegar a acuerdos que impliquen que todos remen en la misma dirección, y que implican adoptar parte de esos comportamientos tan valorados en las nuevas ideologías de gestión: flexibilidad, pasión por el cliente, etc., sin realmente presentar una valoración realista de los pros, contras e intensidades con las que dichas medidas pueden implantarse.

\subsection{La «Nueva Cultura de Empresa», ADEGI y el Gobierno Vasco}

La "Nueva Cultura de Empresa» de ADEGI ha sido acogida muy positivamente por el resto de socios de Confebask, que la han tratado de difundir entre sus asociados, con un éxito importante. ADEGI incluso instituye premios que galardonan algunos de los ejemplos más acabados del cambio cultural que proponen desarrollar. Más y más empresas están implantando este modelo (EFE, 2015). Pero la realidad es que, pese a las buenas palabras del documento, la "Nueva Cultura de Empresa» no ha estado exenta de controversia. Algunos de los procesos de implantación han sido muy polémicos, como ya se ha visto en algunas investigaciones: es el caso de DHL-Mercedes o Sidenor Azkoitia, esta última, para más inri, premiada por ADEGI, sobre los que hay publicados estudios de enorme interés (ver Las Heras, 2018; Martín, 2019) en los que se aprecia que las "Nuevas Culturas de Empresa» de estas organizaciones son ejemplos paradigmáticos de malas prácticas antisindicales. Y es que, pese a la imagen idílica que se ha dado de este cambio cultural, la realidad es que detrás de esta transformación se encuentra un intento por parte de la patronal de minimizar 
el rol sindical mediante un cambio en las relaciones laborales y en la comunicación con los trabajadores y sus representantes. No obstante, desde el Gobierno Vasco, el análisis es muy diferente: la «Nueva Cultura de Empresa» sería una herramienta de enorme utilidad para llevar su programa político y económico (acusado de neoliberal por ELA), y ha orientado su estrategia a apoyar y favorecer la difusión de este nuevo modelo de gestión. Ello lo ha hecho mediante dos ejes principales: por un lado, acudir de forma entusiasta a las Jornadas organizadas de ADEGI dedicadas a esta filosofía gerencial y, por otro, tratar de crear un marco institucional que permita que dicha «Nueva Cultura de Empresa» pueda desarrollarse sin trabas ni cortapisas.

El Gobierno Vasco del PNV y particularmente su Consejera de Desarrollo Económico y Competitividad Arantza Tapia han apoyado sin fisuras la «Nueva Cultura de Empresa». La Consejera, que acude anualmente a las Jornadas que organiza ADEGI para premiar las mejores prácticas de esta nueva cultura empresarial, lo considera como un trampolín para la captación del "talento», otra de las palabras favoritas de los gurús de empresa, y ha mostrado auténtico entusiasmo hacia estas ideas. En unas declaraciones recientes, consideraba que la "Nueva Cultura de Empresa» podría suponer para Euskadi un empuje similar al de la nueva gastronomía de Arzak, Berasategui y compañía (Diario Vasco, 2019). El paralelismo todo hay que decirlo es interesante porque, junto a la emergencia de estos restaurantes con estrellas Michelin, surgió, en muchos restaurantes de esa gama, una política de personal basada en becarios aprendices que trabajan sin sueldo alguno, solo a cambio de alojamiento y comida, lo que ha escandalizado a parte de la opinión pública (Brunat, 2017). Esta nueva cultura de empresa, sin la presencia de sindicatos combativos que sirvan de contrapeso, podría llevar a la larga a un escenario si bien no tan truculento si al menos parecido, con una más que probable precarización de las condiciones laborales. De hecho, algunos de los premiados por las Jornadas como ejemplos excelsos de implantación de dicha cultura son ejemplos, también, de prácticas más que criticables, como ya se indicó anteriormente.

El otro gran eje de actuación ha sido, sin duda, la modificación del marco del diálogo social. Ya desde el año 2014, se comienza a plantear desde el Gobierno Vasco una propuesta de un nuevo modelo de relaciones laborales y de diálogo social, y en el que se empiezan a realizar una serie de «advertencias». En el documento de dicha propuesta, en sus páginas 15 y 16, se menciona que, aunque los agentes sociales tienen autonomía a la hora de proveer de contenido las relaciones laborales, «esto no significa que los poderes públicos deban permanecer ajenos o neutrales en este espacio» (Gobierno Vasco, 2014: p. 15). Esto se justifica no solamente por el hecho de que el poder regulatorio que construyen los agentes sociales (en virtud del principio de extensión de los convenios colectivos), sino porque forman parte del entramado institucional y reciben recursos públicos. Así, en la propuesta se especifica lo siguiente: 
...un esquema de negociación que olvide esta dimensión cuasi-pública (o al menos no estrictamente privada) de los agentes sociales mayoritarios parte de un diagnóstico equivocado e introduce una distorsión que desde el ámbito público no debe pasar inadvertida, sino que ha de ser denunciada de manera activa (íbid., p. 16).

No cabe duda de que este punto parece un aviso a navegantes. Hay agentes sociales (y no es difícil pensar que se está refiriendo, de forma evidente, a ELA) que, de acuerdo con el Gobierno Vasco, utilizarían su rol como legítimos participantes en el diálogo social de una forma perversa, y dicho comportamiento debe ser, por ello, denunciado con el fin de ser reconducido. La propuesta que se hace para modificar el diálogo social va a orientarse, fundamentalmente, a construir un marco de negociación que permita de alguna forma esquinar el escollo del sindicalismo más reivindicativo. Esto se plasmará en un Decreto, aprobado a principios de este año, que comprende una serie de medidas muy relevantes y que afectaban, de forma particular, al sindicato ELA una vez que es el mayoritario. En primer lugar, se hace referencia a la necesidad de armonizar e institucionalizar el diálogo social en la CAPV tal y como se hace en el resto de países europeos, con lo que se da a entender que el Gobierno Vasco es un gobierno moderno y hace lo que debe (entre otras cosas, adaptarse a la filosofía de la flexiguridad o flexiseguridad de la UE). En segundo lugar, su objetivo es que los acuerdos del diálogo social se firmen, a partir de ahora, con la participación de al menos un representante de los agentes sociales. Dado que en la CAPV son cuatro los sindicatos más representativos (ELA, LAB, CCOO y UGT, por este orden), esto significaría que la firma de UGT, que tiene el 10\% de representación, sería suficiente para validar acuerdos, lo que implicaría que se podría burlar, sin ningún problema, la mayoría de ELA, pudiendo alcanzar acuerdos que no contarían con el respaldo mayoritario de los representantes de los trabajadores vascos. En el texto, además, parece inferirse que el objetivo del diálogo social es el de «ser responsable», lo que significaría, de forma velada, aceptar y compartir las políticas del gobierno. Se limita además los temas a tratar en el diálogo social, circunscribiéndolo a cuestiones limitadas y obviando el debate sobre temas más amplios como la política económica, industrial y social (hay que recordar que Confebask ya intentó quitar la condición de sindicatos a ELA y LAB, por posicionarse sobre el TAV: ver ELA, 2014).

\section{Conclusiones}

La «Nueva Cultura de Empresa» es, como hemos podido leer a partir de sus textos, un proyecto de transformación de las relaciones laborales en el País Vasco, auspiciado por ADEGI pero muy bien acogido tanto por Confebask como por el Gobierno Vasco por cuanto se dirige a «resolver» un problema persistente en los últimos años, que es el de la conflictividad laboral. La adaptación 
de la economía vasca a los desafíos del siglo Xxi ha sido interpretada por parte de patronales y gobierno autonómico como la necesidad de implantar una nueva cultura más flexible y «líquida» (por utilizar la feliz expresión de Bauman, 2003) tanto en las empresas como en el diálogo social en Euskadi, en sintonía con cambios similares en el resto de Europa en línea con el pensamiento hegemónico neoliberal. La estrategia del sindicato mayoritario ELA de convertirse en un contrapoder y un elemento de contención frente a estas estrategias ha derivado en el enquistamiento de un conflicto y la apuesta por parte de la parte empresarial de nuevas filosofías de recursos humanos que amenazan el marco del propio sistema de relaciones industriales. La «Nueva Cultura de Empresa» es, en este sentido, su estrategia más llamativa. Se trata de un proyecto con un fuerte carácter ideológico, y que trata de modificar las relaciones de poder existentes tanto dentro de las empresas vascas (a partir de una suerte de guerra cultural) como en el marco legal que articula el diálogo social en Euskadi. Si tuviéramos que hacer un resumen de sus propuestas, este sería el siguiente:

1. En primer lugar, el deseo de cambiar la dinámica de las relaciones laborales dentro de la empresa. El objetivo es superar el conflicto con los sindicatos mediante la sustitución de la negociación con el comité de empresa (que se presume dominado por un sindicato muy conflictivo para ellos, como ELA) por una cultura empresarial en la que la gerencia se dirige directamente a cada trabajador y trata de involucrarlo en un proyecto compartido. Esto es, se trata de sustituir conflicto por cooperación.

2. Para conseguir pasar del conflicto a la cooperación (de la sokatira a la trainera) la empresa va a sustituir el diálogo interno por una suerte de nueva cultura empresarial, una especie de ideología interna de la organización en la que se repite como un mantra que todos estamos en el mismo barco, que en la empresa la relación es de confianza, que hay que trabajar en equipo, llevarnos bien, etc. Toda esta cultura está inspirada en las ideologías gerenciales o del management que vimos en la primera parte del artículo. El objetivo no declarado de forma explícita, aunque sí implícita, es el de ningunear al sindicato y dirigirse directamente a los trabajadores, con el fin de persuadirles a que acepten nuevas condiciones de trabajo apelando a la necesidad de flexibilidad, de adaptarse al mercado, etc. En este sentido, el objetivo es integrar, culturalmente, a los trabajadores en la organización, buscando que abracen nuevas ideas que los alejen de la reivindicación y los sindicatos.

3. Todo esto tiene como objetivo incrementar la flexibilidad en la empresa vasca en términos salariales (con la introducción de elementos variables ligados a la marcha de la empresa), de jornada, funcionales, etc. Aunque se presenta como una estrategia de supervivencia para la empresa, no está garantizado (visto lo visto) que a largo plazo no conlleve un deterioro generalizado de las condiciones de trabajo. 
4. Para facilitar la imposición de la «Nueva Cultura de Empresa», desde las autoridades vascas se está facilitando además, de forma independiente, la puesta en marcha de un nuevo marco de relaciones laborales que, por lo que parece, tiene la intención de reformar en profundidad el diálogo social en la CAPV. El sindicato ELA, de forma más que probablemente acertada, ha señalado que estas propuestas pretenden debilitar, en particular, a su combativo sindicalismo, al permitir la firma de convenios con las minorías sindicales, lo que serviría a patronal y gobierno para sortear las resistencias del sindicato mayoritario (ELA, 2018).

El objetivo, por tanto, de esta "Nueva Cultura de Empresa» parece claro: imponer una nueva cultura dentro de la empresa en línea con las ideologías gerenciales, con el fin de enterrar el conflicto interno y forzar a los trabajadores a la cooperación con la dirección. Ello implica desarrollar una estrategia de comunicación empresarial dirigida a subrayar las bondades del nuevo sistema frente a las relaciones laborales tradicionales (donde el comité de empresa negocia como representación de los trabajadores), ninguneando así a los sindicatos. Esto irá acompańado de reformas en el marco del diálogo social que permitirían sortear desde luego a ELA, el actor más combativo frente a esta política, con el objetivo de debilitarlo, pero que sería una amenaza más que potencial para el resto de las fuerzas sindicales. Por el momento, en algunas de las experiencias en marcha de la «Nueva Cultura de Empresa», lo que se ha generado es un ataque durísimo a la negociación colectiva y una serie de medidas abusivas por parte de las direcciones de las empresas, que se han saldado con una resistencia numantina por parte de ELA y sus delegados en la defensa de los derechos de los trabajadores de las empresas afectadas (ver Las Heras, 2018).

A la hora de reflexionar sobre estas nuevas prácticas gerenciales, hemos de tener presente que la "Nueva Cultura de Empresa» no es solamente una ambición de ADEGI, o de Confebask, o incluso del Gobierno Vasco: se trata de un proyecto coherente con una línea de pensamiento que representa una de las facetas principales de lo que conocemos como gerencialismo, una suerte de producto de su tiempo, que captura el zeitgeist neoliberal. La "Nueva Cultura de Empresa» es, de este modo, ideología gerencial en estado puro, y lo que va a hacer es reproducir unas alusiones vagas a la confianza, las personas, el talento y los proyectos compartidos de forma machacona, con el fin de convencer a la sociedad de que con estas medidas se va a garantizar la competitividad y, desde aquí, la generación de riqueza y bienestar. Esto incide en cómo se ve, además, el papel de los sindicatos, cuyo rol de contrapoder trata de ser erosionado, al entenderlos como instituciones innecesarias, que ponen freno a la libertad y a la iniciativa empresarial. Esta erosión solamente podrá ser detenida si las fuerzas sindicales son conscientes de la amenaza que los nuevos discursos de la empresa, recogidos en las filosofías gerenciales, suponen para ellos, y les presentan la correspondiente batalla, que no 
solamente podrá basarse en las clásicas movilizaciones y la solidaridad de las clases trabajadoras en el centro de trabajo, sino que casi con toda seguridad, necesitará también de un esfuerzo adicional en el terreno de la batalla por las ideas, en el clima de guerra cultural que está caracterizando nuestro tiempo presente.

\section{Bibliografía}

ADEGI (2014 y 2017): Guía. Nueva cultura de empresa. Disponible en https://www.adegi. es/guianuevomodelo/ [acceso 22/03/2019).

Alonso, Luis Enrique (1998): La mirada cualitativa en la sociología, Madrid, Fundamentos.

Alonso, Luis Enrique (2014): «El contexto sociopolítico de la crisis económica: límites institucionales y protesta social», en García, Norberto y Ruesga, Santos (coords.), ¿Qué ha pasado con la economía española?, Madrid, Pirámide, 83-116.

Alonso, Luis Enrique y Fernández Rodríguez, Carlos J. (2013a): Los discursos del presente. Un análisis de los imaginarios sociales contemporáneos, Madrid, Siglo XXI.

Alonso, Luis Enrique, Fernández Rodríguez, Carlos J. (2013b): «Los discursos del management: una perspectiva crítica", Lan Harremanak, 28, 42-69.

Alonso, Luis Enrique y Fernández Rodríguez, Carlos J. (2018): Poder y sacrificio: los nuevos discursos de la empresa, Madrid, Siglo XXI.

Alonso, Luis Enrique y Martínez Lucio, Miguel (2006): Employment Relations in a Changing Society: Assessing the Post-Fordist Paradigm, Basingstoke, Palgrave Macmillan.

Bauman, Zygmunt (2003): Modernidad líquida, Buenos Aires, FCE.

Boltanski, Luc y Chiapello, Ève (2002): El nuevo espíritu del capitalismo, Madrid, Akal.

Bourdieu, Pierre (1998): La distinción, Madrid, Taurus.

Brunat, David (2017): «La miseria de ser becario de Adrià, Muñoz o Berasategui: 16 horas a palos y sin cobrar», disponible en https://www.elconfidencial.com/espana/201704-24/los-becarios-de-adria_1371187/ [acceso 21/04/2019].

Collins, David (2000): Management fads and buzzwords, Londres, Routledge.

Conde, Fernando (2009): Análisis sociológico del sistema de discursos, Madrid, CIS.

Deleuze, Gilles (1999): "Post-scriptum sobre las sociedades de control», en Conversaciones, Valencia, Pre-Textos, 277-286.

Diario Vasco (2019): "Tapia pide empresas bien gestionadas ante la pugna mundial del talento", disponible en https://www.diariovasco.com/agencias/paisvasco/201901/18/tapia-pide-empresas-bien-1332023.html [acceso 01/03/2019].

DiMaggio, Paul y Powell, Walter W. (1983): «The iron cage revisited» institutional isomorphism and collective rationality in organizational fields, American Sociological Review 48, 147-160.

Du GaY, Paul (2012): En elogio de la burocracia, Madrid, Siglo XXI.

Dundon, Tony y Rafferty, Anthony (2018): «The (potential) demise of HRM?», Human Resource Management Journal, 28(3), 377-391.

EFE (2015): «El 55 \% de las empresas se suman a la "nueva cultura" de Adegi», disponible en https://elpais.com/ccaa/2015/01/16/paisvasco/1421431692_283303.html [acceso $14 / 02 / 2019]$.

ELA (2014): «La patronal Confebask pretende destruir lo que no controla», en https:// www.ela.eus/es/noticias/la-patronal-confebask-pretende-destruir-lo-que-no-controla [acceso 15/04/2019]. 
ELA (2018): «PNV y PSE-EE desqprecian la representación sindical elegida por la clase trabajadora vasca", disponible en https://www.ela.eus/es/noticias/pnv-y-pse-ee-desprecian-la-representacion-sindical-elegida-por-la-clase-trabajadora-vasca/institucionalizacion-del-dialogo-social-nota.pdf [acceso 29/01/2019].

Elorrieta, Joxe (2016): Una mirada sindical contracorriente. Clase, territorio y nuevas alianzas, Barcelona, Icaria.

Enteman, Willard F. (1993): Managerialism : the emergence of a new ideology, Madison, WI, University of Wisconsin Press.

Fernández Rodríguez, Carlos J. (2007): El discurso del management: tiempo y narración, Madrid, CIS.

Fernández Rodríguez, Carlos J. (2011): «El gato que caza nuestros ratones: China como colección de mitologías», Papeles de Relaciones Ecosociales y Cambio Global, 115, 79-88.

Fernández Rodríguez, Carlos J. (2013), «The Learning Environment and the Politics of Globalization - Consultants and business schools between destandardization and rhetoric», en Martínez Lucio, Miguel (Ed.), International Human Resource Management: an Employment Relations Perspective, Londres, Sage, 181-200.

Fernández Rodríguez, Carlos J. y Gantman, Ernesto (2011): «Importers of Management Knowledge: Spain and Argentina in the 20th century (1955-2008)», Canadian Journal of Administrative Sciences, 28(2), 160-173.

Fernández Rodríguez, Carlos J., Ibáñez Rojo, Rafael y Martínez Lucio, Miguel (2016): "The reform of collective bargaining in the Spanish metal and chemicals sectors (2008-2015): the ironies and risks of de-regulating employment regulation", en Koukidaki, Aristea, Tavora, Isabel y Martínez Lucio, Miguel (Eds.), Joint regulation and labour market policy in Europe during the crisis, Bruselas, ETUI, 499-553.

Fernández Rodríguez, Carlos J. y Martínez Lucio, Miguel (2014): «El discurso del despido libre en Espańa: una reflexión sobre el papel de los mitos y los prejuicios en las políticas de empleo españolas», Cuadernos de Relaciones Laborales, 32 (1), 191-219.

Fernández Rodríguez, Carlos J. y Medina-Vicent, Maria (2017): "Los nuevos discursos del management: difusión, impactos y resistencias», Recerca: Revista de Pensament I Análisi, 20, 7-14.

Fernández Rodríguez, Carlos J. y Serrano Pascual, Amparo (coords.) (2014): El paradigma de la flexiguridad en las politicas de empleo españolas: un análisis cualitativo, Madrid, CIS.

FundaCión FOESSA (2014): VII Informe sobre exclusión y desarrollo social en España, Madrid, Fundación FOESSA.

Gantman, Ernesto (2005): Capitalism, Social Privilege and Managerial Ideologies, Aldershot, Ashgate.

García, Norberto y Ruesga, Santos (coords.) (2014): ¿Qué ha pasado con la economía española?, Madrid, Pirámide.

Harvey, David (2007): Breve historia del neoliberalismo, Madrid, Akal.

HuCZYNski, Andrezj (1993): Management gurus: what makes them and how to become one, Londres, Routledge.

Keune, Maarten y Serrano Pascual, Amparo (Eds.) (2014): Deconstructing Flexicurity: Towards New Concepts and Approaches for Employment and Social Policy, Oxon, Routledge.

Kipping, Mathias y Engwall, Lars (eds.) (2002): Management Consulting: Reference and Dynamics of a Knowledge Industry, Oxford, Oxford University Press.

KuIKaUER, Thomas (2015): «What Is Managerialism?», Critical Sociology, 41(7-8), 1103-1119. 
Kortabarria, Germán (2016): No pudimos ser amables. ELA 1976-2006, Arre, Pamiela.

Laparra, Miguel y Pérez Eransus, Begoña (coords.) (2013): Crisis y factura social en Europa: Causas y efectos en España, Barcelona, La Caixa.

Las Heras, Jon (2018): ¿Democracia sin sindicatos? Trabajadoras en DHL-Mercedes dicen NO a una doble escala, Documento 41, Bilbao, Manu Robles-Arangiz Institutua Fundazioa.

Lash, Scott, y Urry, John (1987): The End of Organized Capitalism, Oxford, Polity Press.

Laval, Christian, y Dardot, Pierre (2013): La nueva razón del mundo. Ensayo sobre la sociedad neoliberal, Barcelona, Gedisa.

Martín, Xabier (2019), Nueva Cultura de Empresa, viejo Caballo de Troya, Documento 43, Bilbao, Manu Robles-Arangiz Institutua Fundazioa.

Mazza, Carmelo y Álvarez, José Luis (2000): «Haute couture and Prêt-à-Porter: The popular press and the diffusion of management practices», Organization Studies, 21(3), 567-588.

Meardi, Guglielmo (2014): «Employment Relations under External Pressure: Italian and Spanish Reforms in 2010-12», en Hauptmeier, Marco y Vidal, Matt (eds.), Comparative Political Economy of Work, Basingstoke, Palgrave Macmillan, 332-350.

Micklethwait, John y Wooldridge, Adrian (1998): La hora de los gurús: visionarios y nuevos profetas de la gestión empresarial, Madrid, Alianza.

Parker, Martin (2002): Against Management, Cambridge, Polity Press.

PriceWaterhouseCoopers (20 I 8): «Temas candentes de la economía vasca La visión de los empresarios». Disponible en https:/www.pwc.es/es/publicaciones/economia/assets/temas-candentes-economia-vasca.pdf [acceso 18/03/2019).

Revilla, Juan Carlos y Tovar Martínez, Francisco José (2011): «El control organizacional en el siglo XXI: en busca del trabajador autodisciplinado", Revista española de investigaciones sociológicas, 135, 47-68.

Rocha, Fernando (2014): «Crisis and Austerity Policies in Spain: Towards an Authoritarian Model of Industrial Relations", en RochA, Fernando (ed.) The New EU Economic Governance and its Impact on the National Collective Bargaining Systems, Madrid, CCOO, 175-204.

Santos Ortega, Antonio y Muñoz-Rodríguez, David (2018): «¿Qué es esa cosa llamada intraemprendedor? Gestión del trabajo en el capitalismo cognitivo y concepciones emprendedoras», Cuadernos de Relaciones Laborales, 36(2), 285-303.

SARATXaga, Koldo (2007): Un nuevo estilo de relaciones: para el cambio organizacional pendiente, Madrid, Pearson.

WeduIn, Linda (2006): Ranking Business Schools: Forming Fields, Identities and Boundaries in Management Education, Cheltenham, Edward Elgar.

Willmott, Hugh (2007): «La fuerza es la ignorancia, la esclavitud es la libertad: la gestión de la cultura en las organizaciones modernas», en Fernández Rodríguez, Carlos J. (Ed.), Vigilar y Organizar: una introducción a los Critical Management Studies, Madrid, Siglo XXI, 103-160. 